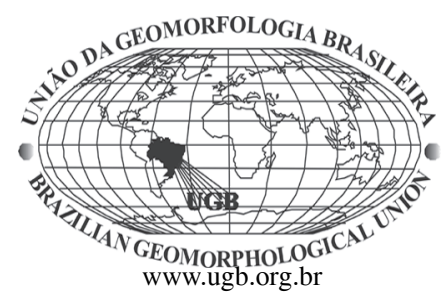

\title{
NÍVEIS DE TERRAÇOS FLUVIAIS E DEPÓSITOS SEDIMENTARES CORRELATIVOS NO ALTO VALE DO RIO DAS VELHAS, QUADRILÁTERO FERRÍFERO, MG
}

\author{
Gisele Barbosa dos Santos \\ MSc. em Geografia e Análise Ambiental - IGC/UFMG - Av. Antônio Carlos, 6627 - \\ Cep 31270-901 - Belo Horizonte-MG - e-mail: giselebsantos@oi.com.br

\begin{abstract}
Antônio Pereira Magalhães Jr.
Departamento de Geografia - Instituto de Geociências da UFMG - Av. Antônio Carlos, 6627 - Cep 31270-901 Belo Horizonte-MG - e-mail: magalhaesufmg@yahoo.com (contato para correspondências)
\end{abstract} \\ Luis Felipe Soares Cherem \\ Mestrando em Análise e Modelagem de Sistemas Ambientais - IGC/UFMG - Av. Antônio Carlos, 6627 - \\ Cep 31270-901 - Belo Horizonte-MG - e-mail: luis.cherem@gmail.com
}

\begin{abstract}
Resumo
O alto vale do Rio das Velhas está inserido nos limites do Quadrilátero Ferrífero. A rede de drenagem reflete o forte controle litoestrutural e apresenta canais com feições típicas de ambientes montanhosos. Este trabalho visou investigar a geomorfologia fluvial da área em dois contextos temporais a saber: a história da evolução fluvial pretérita evidenciada pelos paleoníveis deposicionais (níveis de terraços); e a dinâmica fluvial recente, evidenciada pelo nível de planície e pelo ambiente de leito. A partir da investigação dos níveis e sequências deposicionais associadas pretendeu-se apresentar um panorama da geomorfologia fluvial do alto Rio das Velhas, o qual ainda não possuía nenhum estudo deste gênero. Foram identificados quatro níveis deposicionais aluviais, sendo três níveis de terraços - Nível Superior (T3), Nível Intermediário (T2) e Nível Inferior (T1) - e um Nível de planície. Os registros sedimentares dos terraços mais antigos são pouco representativos e fragmentados espacialmente . Os níveis apresentam tipologias variadas - escalonado, embutido, de recobrimento - refletindo o condicionamento neotectônico ao longo do Vale que associa o soerguimento do Escudo Brasileiro com a movimentação diferencial de blocos. Nos pontos de movimentação mais intensa, o Nível de Terraço Inferior e o Nível de planície são do tipo escalonado em relação aos níveis imediatamente mais antigos, enquanto nos blocos mais estáveis os níveis encontram-se embutidos ou o Nível de Terraço Inferior é de recobrimento.
\end{abstract}

Palavras-chave: geomorfologia fluvial, Rio das Velhas, Quadrilátero Ferrífero.

\begin{abstract}
The upper Rio das Velhas watershed drains the internal area of Quadrilátero Ferrífero Domain. The morphology of its streams demonstrates a hard geologic control on the relief and fluvial dynamics, by presenting features which are common in mountainous areas. This paper presents an investigation into the upper Rio das Velhas valley focusing two different time scales. Firstly, the alluvium deposits' features, morphology and levels are surveyed to comprehend its Cenozoic history. After that, floodplain and bed sediments are also surveyed for studying the nowadays valley dynamics, specifically after its human occupation since the early $18^{\text {th }}$ century. This survey helps understanding the fluvial geomorphology of this domain, because of its conceptual and methodological structure which had never been applied to the area. Results present a terraced fluvial succession scenery with three terrace levels and one floodplain, confirming previous studies of the downstream middle valley. The superior (T3) and the middle (T2) terraces are erosional and strath ones (cut-in-bedrock terraces). The low one (T1) has various relations to the floodplain, which can be cut-in-bedrock, recovered by floodplain deposits or a fill level in a smaller stream section. The superior terrace is the only one that is not located along the entire valley due to aging processes. The strath levels indicate a permanent regional uplifting (Brazilian Shield) where as the typological variation at the low terrace (T1) indicates a differential blocks movement along this valley.
\end{abstract}

Keywords: fluvial geomorphology; Rio das Velhas, Quadrilátero Ferrífero. 


\section{Introdução}

Os estudos de geomorfologia fluvial e Quaternário no Brasil são comumente realizados tendo como objeto de estudo sistemas fluviais de maiores dimensões (Santos e Stevaux, 2000; Latrubesse 2003, Latrubesse e Franzinelli, 2005; Latrubesse et al., 2005; Stevaux et al., 2006). São menos comuns os estudos em sistemas fluviais de contextos montanhosos onde os registros sedimentares são pouco representativos e fragmentados espacialmente. A maior parte dos estudos de registros deposicionais fluviais se vale da identificação e caracterização de sequências aluviais presentes em níveis de terraços e de planície. A literatura aponta diferentes tipologias de terraços e condições para a sua formação. Neste sentido, terraços escalonados, embutidos e de recobrimento vêm auxiliando a reconstituição do passado geomorfológico de vales fluviais em todo o mundo (Bridge, 2003; Kondolf \& Piégay, 2003; Charlton, 2008).

Esta realidade de ambientes fluviais em contextos montanhosos é encontrada na maior parte do Quadrilátero Ferrífero, porção central do estado de Minas Gerais. O Quadrilátero é um dos mais conhecidos domínios geológicos e geomorfológicos do Brasil, e tem os seus limites praticamente coincidentes com a bacia do alto Rio das Velhas, um dos principais afluentes do Rio São Francisco. A ocupação do alto vale, iniciada em meados do século XVII, foi marcada por pressões humanas sobre os ambientes fluviais por meio principalmente da exploração mineral durante o Ciclo do Ouro, contribuindo para impactos na dinâmica fluvial. Atualmente, a bacia tem sua importância reforçada pelo fato de responder pelo abastecimento de água de grande parte da população da Região Metropolitana de Belo Horizonte. Apesar de sua relevância histórica e geográfica no cenário brasileiro, o alto vale do Rio das Velhas começou, apenas recentemente, a ser objeto de estudos sistemáticos para a reconstituição de eventos geomorfológicos cenozóicos, com base em registros deposicionais. Foram iniciadas, a partir de 2006, pesquisas no Departamento de Geografia da UFMG enfocando a identificação, interpretação e o mapeamento de níveis e sequências deposicionais no vale do Rio das Velhas e de seus principais afluentes. Os resultados podem, deste modo, auxiliar a reconstituição de eventos geomorfológicos denudacionais e deposicionais no Quadrilátero Ferrífero e subsidiar comparações com trabalhos realizados à jusante.

Dentre os trabalhos relacionados à geomorfologia fluvial no alto vale do Rio das Velhas destacam-se os trabalhos de Magalhães Jr. (1993; 1994) e Magalhães Jr e Saadi (1994) que reconstituíram a evolução cenozóica do alto-médio vale adotando a mesma metodologia deste trabalho. Mais recentemente, podem ser citados os trabalhos de mapeamento e identificação de zonas de sedimentação e erosão em ambiente de calha realizados por Lana (2004), Castro et al. (2005) e Lana \& Castro (2005). Outros estudos enfocaram afluentes do Rio das Velhas na área (Valadão e Silveira, 1992; Bacellar, 2000).

Este trabalho pretende contribuir para a compreensão da geomorfologia fluvial da bacia do Rio das Velhas, especificamente no Quadrilátero Ferrífero. Buscou-se investigar os paleoeventos deposicionais do alto vale do Rio das Velhas a partir da identificação, mapeamento e interpretação de níveis e sequências sedimentares aluviais. A comparação dos registros antigos com os níveis e depósitos recentes é utilizada como ferramenta para considerações a respeito da evolução e do comportamento têmporo-espacial dos processos geomorfológicos no Vale.

\section{Material e Métodos}

Em termos metodológicos, o estudo foi inicialmente baseado na interpretação de fotos aéreas ortorretificadas datadas de 1989 e com escala 1:30000. Diversos trabalhos de campo foram realizados para levantamento e confirmação in locu das informações. Os níveis deposicionais foram devidamente georreferenciados com o auxílio de um GPS, seguidos de registros fotográficos. Os registros sedimentares foram analisados quanto ao arranjo e distribuição espacial, tipologias e características das fácies. Seixos foram caracterizados quanto à textura, litologia, grau de arredondamento, homogeneidade, organização e textura da matriz. As fácies de textura argila a areia foram caracterizadas principalmente quanto à granulometria (análises no Laboratório de Geomorfologia da UFMG), espessura, cor, presença de matéria orgânica e de estruturas sedimentares. As análises granulométricas e de matéria orgânica foram realizadas no Laboratório de Geomorfologia da UFMG. As primeiras via esborroamento e peneiramento, e as últimas por meio do método de Walkley-Black. Foram construídos perfis estratigráficos representativos para cada nível deposicional. A base utilizada para o mapeamento foi um mosaico de ortofotos com escala de 1:8000, datadas de 1989 e cedidas pelo Departamento de Cartografia do Instituto de Geociências (Laboratório de Geoprocessamento) da Universidade Federal de Minas Gerais. O mapeamento foi feito com o auxílio do software ARC VIEW 9.

\section{Caracterização da Bacia do Alto Rio das Velhas}

A bacia do Rio das Velhas localiza-se na porção central de Minas Gerais, com uma área de $27.867,2 \mathrm{~km}^{2}$. O Rio das Velhas nasce no município de Ouro Preto e deságua no rio São Francisco. A bacia do Alto Rio das Velhas coincide com o domínio do Quadrilátero Ferrífero, tendo o município de Ouro Preto como o limite sul e Belo Horizonte, Contagem e Sabará como limites ao norte (Figura 1). Após percorrer um trecho montanhoso próximo a Ouro Preto, o Rio das Ve- 
lhas corta a porção interior suavizada do Quadrilátero Ferrífero, modelada em rochas cristalinas friáveis. Mais à jusante, no município de Rio Acima, o vale apresenta um trecho fortemente encaixado típico de ambientes de elevada energia. Em todo o Quadrilátero há um forte condicionamento geológico da rede de drenagem.

O quadrilátero Ferrífero é delimitado por serras sustentadas pelas rochas mais resistentes do Supergrupo Mi- nas, configurando-se como bordas de anticlinais escavadas e sinclinais suspensas derivadas da erosão diferencial nos grandes dobramentos regionais. O embasamento cristalino (granitos, gnaisses, migmatitos) é recoberto por uma sequência arqueana tipo "greenstone belt" (Supergrupo Rio das Velhas), e duas sequências proterozóicas metassedimentares: Supergrupo Minas e Itacolomi.
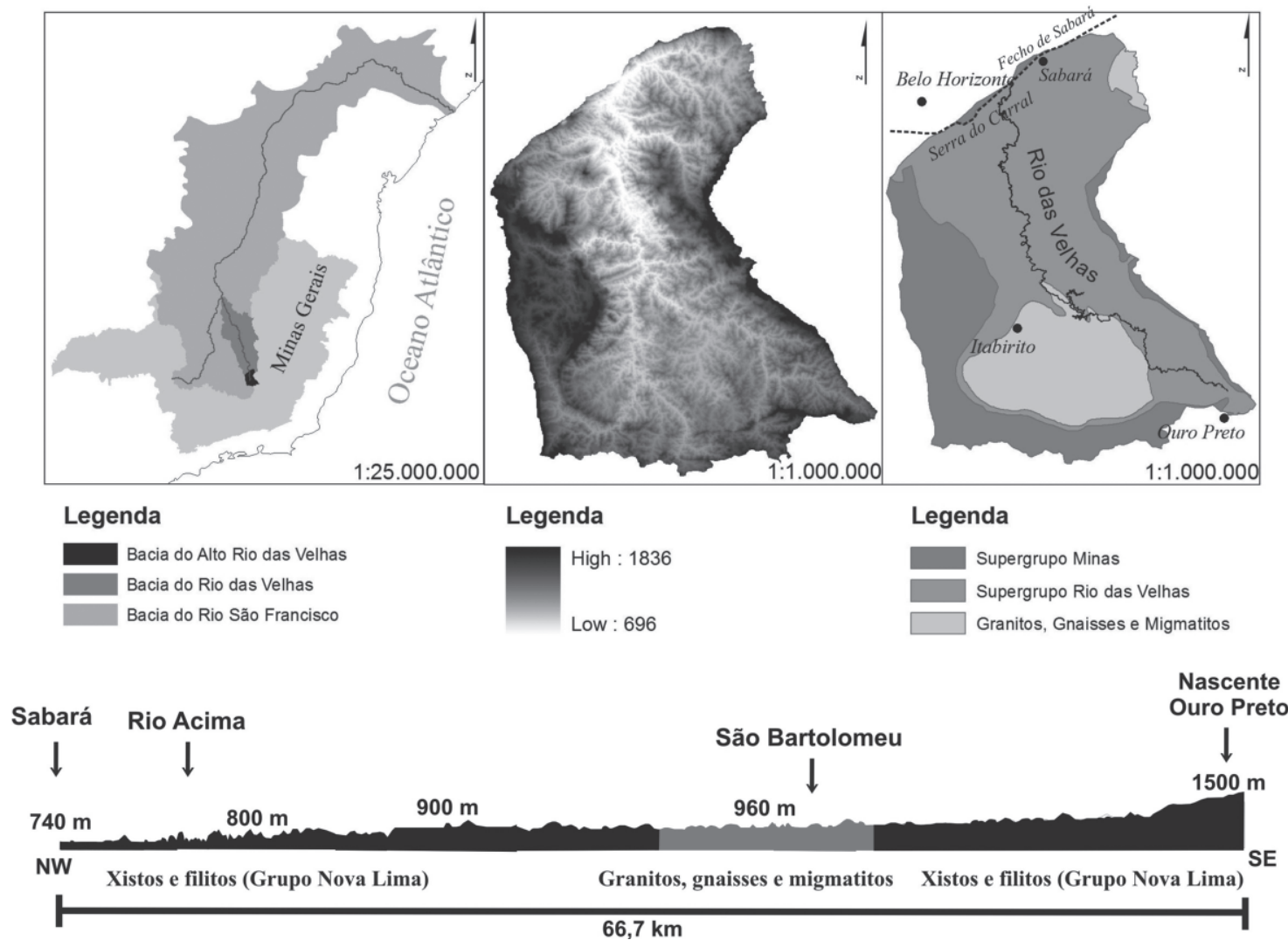

Figura 1 - Quadro altimétrico-geológico do Quadrilátero Ferrífero e perfil longitudinal do Rio das Velhas

O embasamento cristalino constitui-se de um complexo de rochas graníticas arqueadas. A principal estrutura dômica é representada pelo Complexo do Bação, de idade arqueana (Alkmim \& Marshak, 1998), que aflora no interior do Quadrilátero a partir de sua exumação por processos erosivos. Suas rochas friáveis e intemperizadas favoreceram um modelado de colinas suavizadas peculiares na região. A baixa resistência natural das rochas à erosão, intensificada pelas atividades antrópicas, condicionou o desenvolvimento de voçorocamentos que fornecem elevada carga sedimentar às calhas fluviais.

Os compartimentos morfológicos de altitude e grau de dissecação intermediários entre o interior suavizado e as bordas serranas são modelados principalmente sobre as rochas do Supergrupo Rio das Velhas, uma unidade tipo greenstone belt em que destacam-se xistos, grauvacas, quartzitos e conglomerados (Ladeira, 1980). As rochas do Supergrupo Minas sus- tentam os relevos serranos que delimitam o Quadrilátero Ferrífero, destacando-se quartzitos, itabiritos e filitos. Secundariamente, ocorrem dolomitos e calcários.

\section{Níveis e Sequências Deposicionais Fluviais.}

Foram identificados quatro níveis deposicionais aluviais no alto vale do Rio das Velhas, sendo três níveis de terraços - Nível Superior (T3), Nível Intermediário (T2) e Nível Inferior (T1) - e um Nível de planície de inundação. Os registros sedimentares dos terraços mais antigos são pouco representativos e fragmentados espacialmente. A Figura 2 representa a organização espacial transversal dos níveis deposicionais, bem como os perfis estratigráficos característicos. A Figura 3 apresenta os mapas com a distribuição espacial dos níveis. 


\section{Nível de Terraço Superior}

O Nível de Terraço Superior é do tipo escalonado, sendo encontrado pontualmente ao longo do vale. Os terraços escalonados são aqueles assentados diretamente sobre o substrato rochoso e dispostos em patamares altimétricos distintos ao longo da encosta. Apresentam, portanto, o afloramento de rocha sã ou intemperizada nos trechos da encosta que os separam dos níveis de terraços superiores e inferiores (vindo daí a terminologia do escalonamento). Suas características denotam o encaixamento da calha fluvial após a sua formação, permitindo a exposição do substrato rochoso.

A base do Nível de Terraço Superior varia de 35 a 50 metros acima da lâmina d'água atual, em altitudes entre 750 $\mathrm{m}$ e $1000 \mathrm{~m}$. Seus registros são encontrados a aproximadamente $100 \mathrm{~m}$ de distância da calha atual. Esse nível apresenta três lito-fácies principais:

- nível basal de seixos de quartzo e itabirito arredondados, moderadamente selecionados, com tamanho médio variando de 12 a $6 \mathrm{~cm}$ (de montante para jusante), suportados por matriz arenosa; 1,30 m de espessura;

- material areno-argiloso, maciço, coloração vermelho-amarelado, presença de matéria orgânica; espessura de $30 \mathrm{~cm}$.

\section{Nível de Terraço Intermediário}

O Nível de Terraço Intermediário também é do tipo escalonado. A base varia de 10 a $30 \mathrm{~m}$ acima da calha atual ao longo do vale, em altitudes entre 740 e 970 m. São encontradas duas fácies características (Figura 2):

- fácies basal de seixos de quartzo e itabirito sub-arredondados a arredondados, moderadamente selecionados, com tamanho médio variando de 20 a $5 \mathrm{~cm}$ ao longo do vale (de montante para jusante). Os seixos são suportados por matriz de areia fina bruno-avermelhada. Espessura média entre 50 $\mathrm{cm}$ a $1,50 \mathrm{~m}$.

À jusante da área, próximo à Serra do Curral, Magalhães Jr (1993) verificou perfis com elevado percentual de seixos de itabirito (49\%) e quartzo (41\%), além de quartzito $(10 \%)$. O percentual de seixos de quartzo aumenta progressivamente, chegando a $94 \%$ no município de Santa Luzia.

- areia fina bruno-amarelada, sem presença de estruturas aparentes; espessura variando de 50 a $90 \mathrm{~cm}$.

\section{Nível de Terraço Inferior}

O Nível de Terraço Inferior (T1) apresenta diferentes tipologias em relação aos níveis cronologicamente mais próximos (Figura 2). Em relação ao T2 pode ser encontrado do tipo escalonado (denotando encaixamento da calha). Em relação ao Nível da planície pode ser escalonado (encaixamento da calha entre o T1 e a planície) ou pode ser do tipo terraço de recobrimento (sendo recoberto pelo atual nível de inundação). O T1 escalonado em relação à planície foi encontrado próximo a Ouro Preto (distrito de São Bartolomeu) e nas proximidades de Itabirito.

O nível de Terraço Inferior encontra-se em posição muito diversa em relação à calha atual: 0,2 a 24 m. Apresenta três fácies principais:

- fácies basal composta por seixos de quartzo sub-arredondados a arredondados, moderadamente selecionados, com tamanho médio entre 15 e $3 \mathrm{~cm}$ (de montante para jusante), suportados por matriz arenosa amarelada. Presença de seixos de itabirito e quartzito e estruturas plano-paralelas em alguns trechos; $50 \mathrm{~cm}$ de espessura média;

- fácies areno-siltosa, bruno-amarelada, sem presença de estruturas; espessura variando de $20 \mathrm{~cm}$ a 1,50 metros;

- fácies superior composta por seixos de quartzo, quartzito e itabirito ferruginizados, suportados por matriz arenosa amarelada; com $60 \mathrm{~cm}$ de espessura aproximada. Esta fácies indica o reposicionamento da calha fluvial em nível mais elevado à medida que o processo de sedimentação evoluía.

Nos trechos fluviais à jusante do Quadrilátero, próximo a Rio Acima, observa-se que os níveis de terraços Inferior e Intermediário são encontrados pontualmente dentro do vale, havendo quase que exclusiva presença do nível de planície. Em contrapartida, nos trechos a montante da confluência do rio Maracujá, os depósitos dos níveis de terraços Superior e Intermediário encontram-se bem mais preservados.

\section{Nível de Planície}

A dinâmica atual é representada, em termos de ambientes marginais, pelo Nível de planície que se apresenta de dois tipos: nível recobrindo o T1 (Figura 4) e nível embutido no T1. Neste processo de embutimento, a base da planície é a mesma do T1, não tendo havido o encaixamento da calha entre ambos. Não há significativa diversidade na constituição faciológica ao longo do vale, entretanto, a espessura e a largura dos depósitos variam de acordo com o nível de encaixamento do canal. Em geral, a planície apresenta material arenoso pobremente selecionado, bruno-amarelado, havendo abundância de matéria orgânica (raízes) e presença de estruturas plano-paralelas.

Nos trechos em que houve encaixamento da calha entre o T1 e a planície, esta encontra-se escalonada. Porém, onde a planície está embutida no T1, ou o recobre, não houve encaixamento. Este fato deve ser avaliado à luz do nível basal de seixos do T1 que encontra-se pavimentando o leito fluvial atual. Isto indica que, nestes trechos, o nível detrítico pode estar oferecendo resistência ao encaixamento, a partir do processo de encouraçamento da calha (armoring). 
O espessamento dos depósitos de planície após a confluência com o rio Maracujá expressa a importância deste no fornecimento de carga sedimentar para o alto vale do Rio das Velhas. Assim, a dinâmica fluvial atual vem sendo marcadamente condicionada pelos focos de erosão acelerada na bacia do Rio Maracujá. É importante ressaltar a grande variação da largura da planície ao longo do vale: próximo à
São Bartolomeu chega a atingir $180 \mathrm{~m}$ de largura, enquanto à montante da Represa Rio de Pedras a largura se reduz para 40 metros. À jusante da Represa, o Rio encontra-se muito encaixado, estando a calha entalhando o substrato rochoso. Próximo a Rio Acima (à jusante) o nível de planície volta a apresentar maior largura $(60 \mathrm{~m})$.
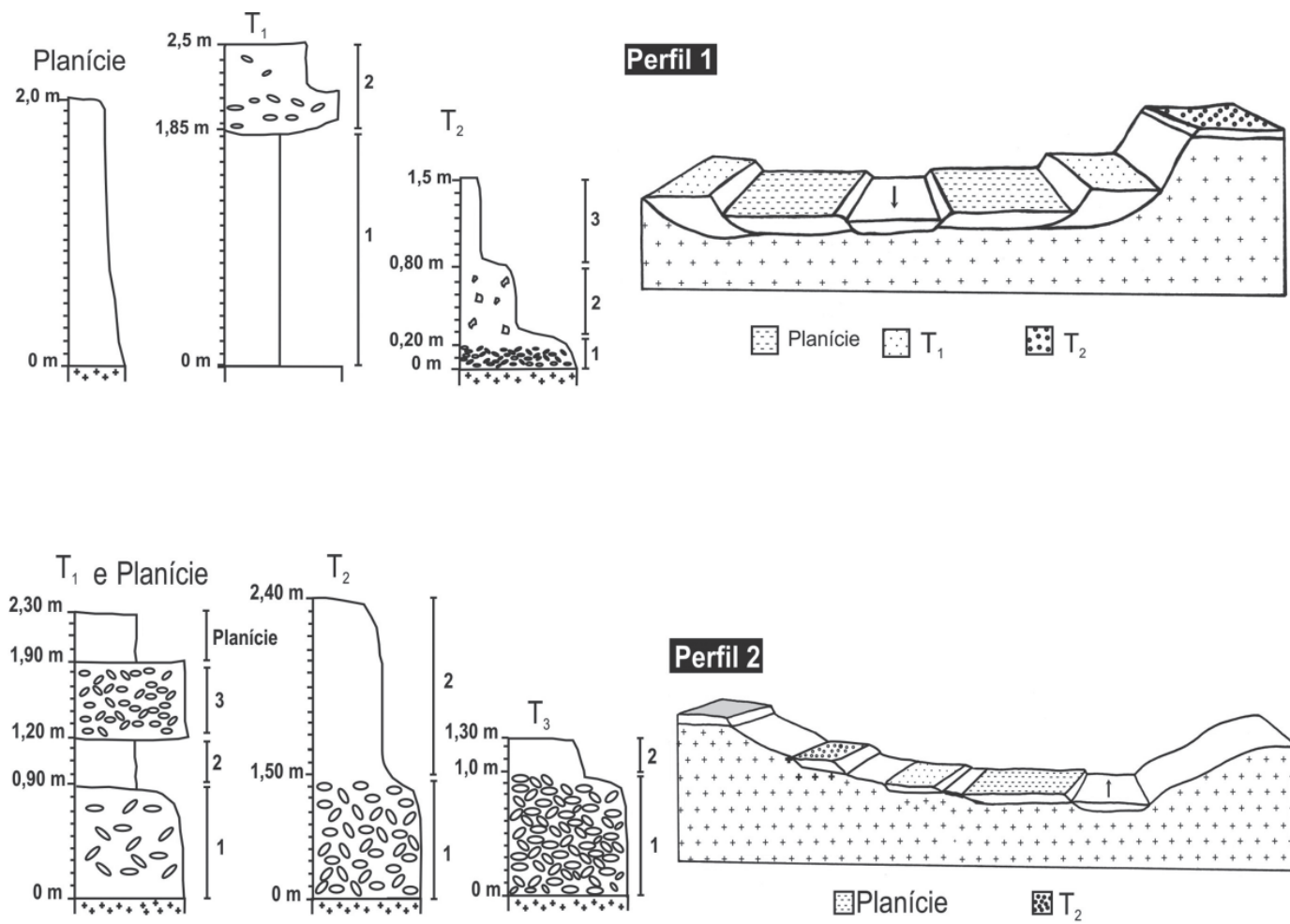

Perfil 2
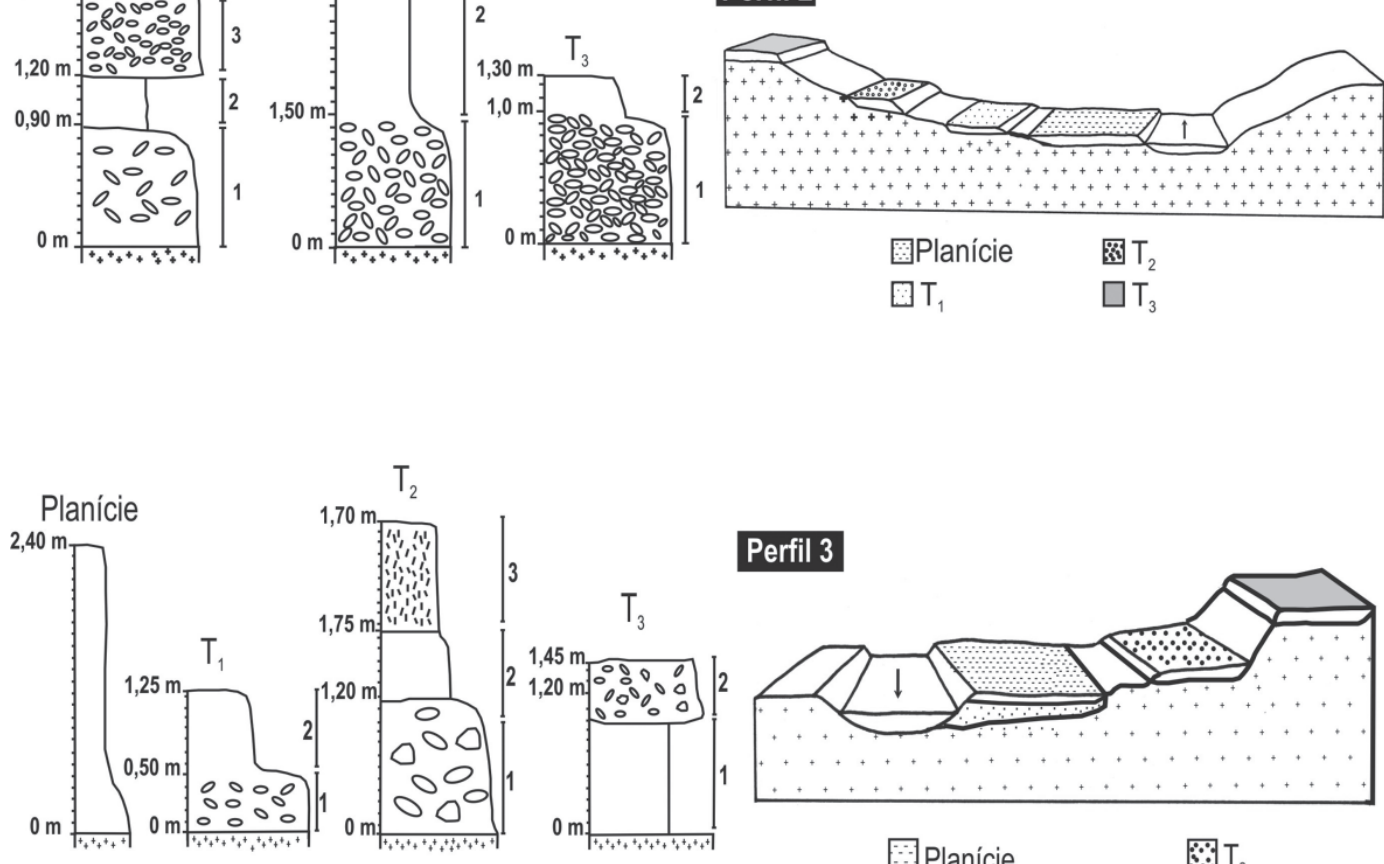

\section{Perfil 3}

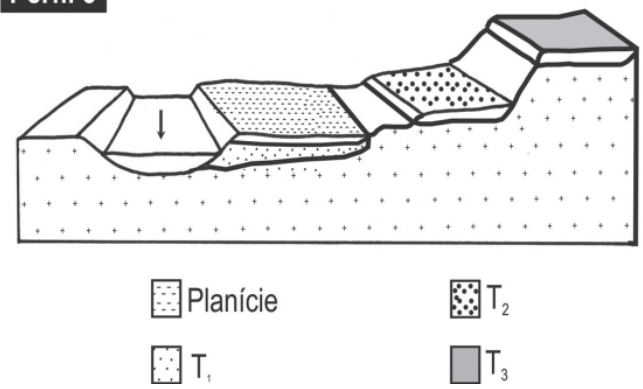

Figura 2 - Seções transversais fluviais e perfis estratigráficos característicos do Alto Vale do Rio das Velhas - Perfil 1: T2 e T1 escalonados e planície embutida no T1; Perfil 2: todos os níveis escalonados; Perfil 3: T3 e T2 escalonados, T1 recoberto pela planície. 


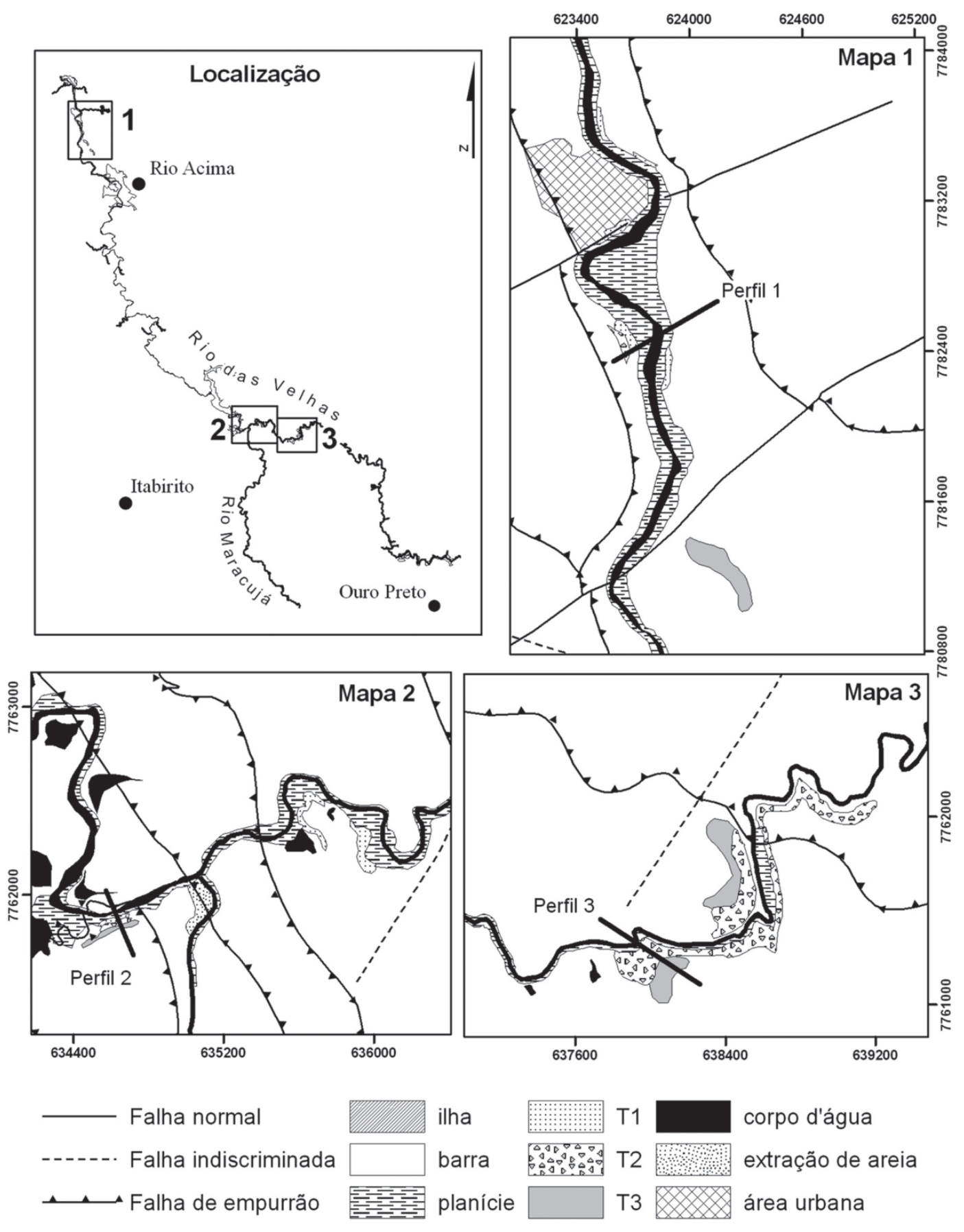

Figura 3 - Distribuição espacial dos níveis deposicionais fluviais. Para a visualização dos perfis transversais, olhar a Figura 2. 


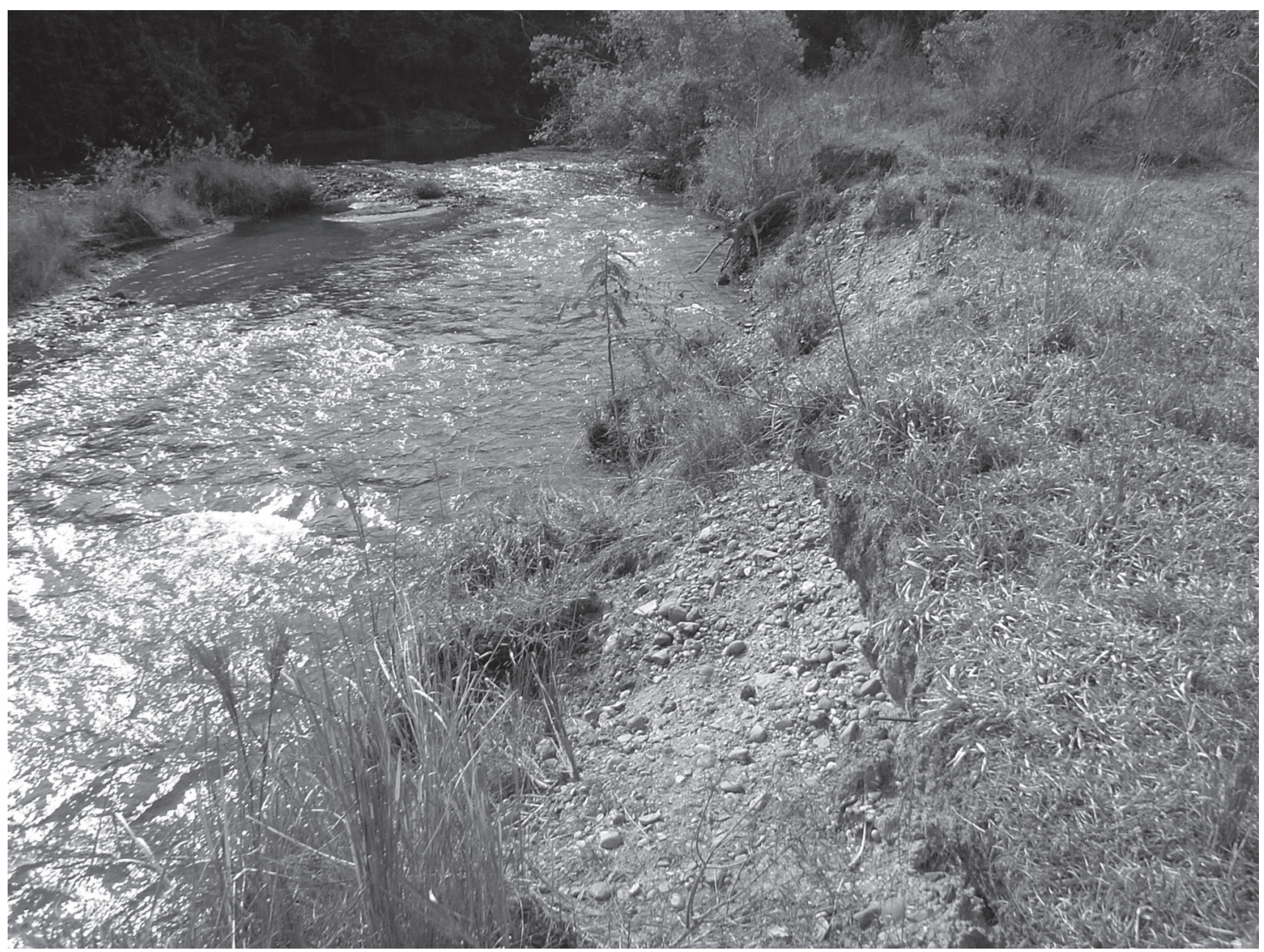

Figura 4 - Trecho fluvial com Nível de planície de inundação recobrindo a fácies de seixos do Nível de Terraço Inferior (T1). Na calha observa-se presença de corredeira.

Os perfis estratigráficos associados aos perfis transversais do Rio das Velhas, na Figura 2, foram descritos a fim de se apresentar um quadro mais preciso da sequência de fácies dos níveis deposicionais. Os perfis estratigráficos associados ao Perfil transversal 1 situam-se em Rio Acima, coordenadas $20^{\circ} 03^{\prime} 0,01^{\prime \prime} \mathrm{S} / 43^{\circ} 48^{\prime} 5,7^{\prime \prime} \mathrm{W}$, na margem esquerda do Rio das Velhas. A calha situa-se em altitude de 720 metros, enquanto as alturas em relação à calha variam de $4 \mathrm{~m}$ na planície, a $20 \mathrm{~m}$ no T1 e $22 \mathrm{~m}$ no T2. Os níveis deposicionais apresentam a seguinte descrição (a numeração das fácies obedece a numeração dos perfis da Figura 2):

\section{Planície:}

(1) Material silto-arenoso (areia fina), marrom acinzentado; presença de matéria orgânica.

\section{Nível de Terraço Inferior (T1):}

(1) Material areno-argiloso (areia fina), marrom amarelado; partes com material mais argiloso com mosqueamentos avermelhados a acinzentados; presença de matéria orgânica.

(2) Material arenoso (areia fina à média), marrom avermelhado; partes com material mais argiloso marrom avermelhado; presença de seixos isolados arredondados a subarredondados de tamanho variado.

\section{Nível de Terraço Intermediário (T2)}

(1) Nível de seixos de quartzo e itabirito arredondados, ferruginizados, suportados entre si, com comprimento médio de $2 \mathrm{~cm}$.

(2) Material areno-siltoso (areia fina) cinza amarelado, com abundantes seixos de filito pouco transportados (angulosos a sub-angulosos).

(3) Material siltoso marrom claro.

Os perfis estratigráficos do Perfil transversal 2 (Figura 2) estão situados em Itabirito, coordenadas $20^{\circ} 14$ ' 3,7' S/ $43^{\circ} 42^{\prime} 31,04^{\prime \prime}$ W. A calha do Rio das Velhas posiciona-se a altitude de 890 metros no local, enquanto o desnível dos níveis deposicionais em relação à calha varia de $3 \mathrm{~m}$ no caso da planície, a $13 \mathrm{~m}$ no T1, $15 \mathrm{~m}$ no T2 e $40 \mathrm{~m}$ no T3. Os níveis deposicionais apresentam as seguintes fácies:

Planície: a planície apresenta aproximadamente 32 metros de largura, sendo marcada por material areno-siltoso marrom (areia muito fina e fina); 


\section{Nível de Terraço Inferior (T1)}

(1) Nível basal de seixos arredondados a sub-arredondados de quartzo e quartzito, com raros de itabirito, suportados entre si, apresentando comprimento médio entre $2 \mathrm{~cm}$ e $7 \mathrm{~cm}$; matriz de areia grossa.

(2) Material areno-argiloso marrom avermelhado (areia fina à média).

\section{Nível de Terraço Intermediário (T2)}

(1) Nível de seixos de quartzo arredondados a sub-arredondados, suportados entre si, com comprimento médio de $30 \mathrm{~cm}$; matriz arenosa fina a média marrom avermelhada.

(2) Material arenoso (areia fina à média) marrom avermelhado.

(3) O número 3 no perfil do T2 representa material coluvionar de cobertura, arenoso-siltoso (areia fina), marrom claro avermelhado.

\section{Nível de Terraço Superior (T3)}

(1) Material areno-argiloso (areia média a grossa) marrom acinzentado, rico em matéria orgânica.

(2) Nível de seixos arredondados, sendo poucos de quartzo e abundantes de itabirito, suportados entre si, com comprimento médio de $10 \mathrm{~cm}$; matriz arenosa (areia fina a média) marrom acinzentada.

O Perfil transversal 3 (Figura 2) localiza-se no distrito de Glaura, pertencente a Ouro Preto, na margem esquerda do Rio das Velhas, entre as coordenadas $20^{\circ} 13^{\prime} 56,7^{\prime}$ 'S $43^{\circ}$ $40^{\prime} 16,69$ 'W. A calha do Rio das Velhas situa-se a uma altitude de 915 metros, apresentando desnível de $4 \mathrm{~m}$ da base da planície e do T1, $12 \mathrm{~m}$ do T2 e $30 \mathrm{~m}$ do T3. Os níveis deposicionais apresentam a seguinte descrição:

Planície: a planície apresenta uma largura de aproximadamente 40 metros no local, sendo caracterizada por material areno-siltoso (areia muito fina) marrom amarelado, com presença de matéria orgânica.

\section{Nível de Terraço Inferior (T1)}

(1) Nível basal de seixos arredondados de quartzo e itabirito, suportados entre si, com comprimento variado entre $4 \mathrm{~cm}$ e $10 \mathrm{~cm}$; matriz arenosa (média à grossa) marrom acinzentada.

(2) Material areno-siltoso (areia muito fina) marrom amarelado.

(3) Nível de seixos de quartzo suportados entre si, com comprimento médio de $10 \mathrm{~cm}$, e poucos seixos de itabirito com comprimento médio de $7 \mathrm{~cm}$; matriz arenosa marrom (areia grossa).

\section{Terraço Intermediário (T2)}

(1) Nível basal de seixos arredondados de quartzo e itabirito com comprimento médio de $10 \mathrm{~cm}$; matriz arenosa (fina à média) marrom claro a avermelhada.

(2) Material arenoso (areia fina à média) marrom acinzentado.

\section{Nível de Terraço Superior (T3)}

(1) Nível basal de seixos de itabirito e poucos de quartzo, arredondados a sub-arredondados, suportados entre si, com comprimento médio de $12 \mathrm{~cm}$; presença de concreções ferruginosas e matéria orgânica.

(2) Material arenoso (areia média a grossa) marrom avermelhado, com abundância de ferro.

No trecho superior do vale estudado, à montante da Represa Rio de Pedras, o leito fluvial atual se configura com uma sucessão de poços (ambientes de baixa energia) e corredeiras (elevada energia). Esta sucessão é típica de diversos sistemas fluviais de contextos montanhosos. Lana (2004) e Lana e Castro (2005) também identificaram sequências de poços e corredeiras no leito do Rio das Velhas em seu alto curso. Estudos realizados por Chin (1999) e Duckson e Duckson (2001) apontam a resistência do substrato ao entalhe do fluxo e as rupturas de declive no perfil fluvial das áreas de cabeceiras, como sendo fatores importantes na existência de sequências de poços e corredeiras em sistemas montanhosos.

No caso do trecho superior do Rio das Velhas no Quadrilátero, a resistência oferecida ao fluxo advém dos seixos que formam a base do $\mathrm{T} 1 \mathrm{e}$ foram exumados pelo fluxo ao remover a fácies fina do terraço. Desde a formação do T1 a calha não consegue encaixar nestes trechos. Com a exumação dos seixos a partir da migração lateral do canal, o leito passou a se constituir de um pavimento detrítico fóssil. Além da textura favorável à resistência à erosão, o nível de seixos está em grande parte concrecionado devido à abundância de ferro na área (rochas itabiríticas).

Estudos no Quadrilátero Ferrífero vêm demonstrando a ocorrência destes processos em diversos vales fluviais (Magalhães Jr et al., 2008). Futuros estudos hidrossedimentológicos poderão investigar se a retenção de sedimentos nos poços contribui para o aumento de energia do fluxo à jusante e, consequentemente, para a erosão da fácies fina do T1. Neste caso, o processo levaria à exumação dos seixos e à formação das corredeiras devido à turbulência e à resistência dos seixos ao fluxo. Portanto, a calha e os ambientes marginais evoluem evoluiriam a partir desta cadeia de processos que envolveria a formação de poços, a erosão do T1, a exumação do pavimento detrítico e a formação de corredeiras. 
A carga sedimentar atual constitui-se basicamente de areia grossa nas corredeiras, enquanto nos poços predomina material silto-argiloso.

\section{Considerações Sobre os Eventos Deposicionais}

A história geomorfológica do Quadrilátero Ferrífero não possui registros sedimentares em cotas superiores a 1000 $\mathrm{m}$. Diversos autores propuseram a existência de remanescentes de superfícies erosivas na área a cotas entre 1.200 e 2.100 m (King, 1956; Barbosa e Rodrigues, 1967; Dorr, 1969, dentre outros). Porém, estes registros são muito restritos e fragmentados espacialmente, reforçando as controvérsias sobre sua existência. O nível erosivo mais consensual continua sendo a Superfície Sul-Americana de King que, no Terciário, teria marcado um importante nível de base de caráter continental. No Quadrilátero, os seus registros morfológicos estariam preservados a cerca de 850 -900 m de altitude.

À dissecação da Superfície Sul-Americana ou de outros paleoníveis seguiu-se o posicionamento da calha do Rio das Velhas nas cotas do Nível de Terraço Superior (1000 a $750 \mathrm{~m}$ ). Altimetricamente este nível pode ser relacionado ao ciclo Velhas mais antigo proposto na área por King, a cotas entre 700 e $750 \mathrm{~m}$. O forte desnivelamento deste nível de terraço na borda da Bacia do Bambuí evidencia a atuação da neotectônica na área (Magalhães Jr, 1993).

Uma nova fase de encaixamento da calha fluvial do Rio das Velhas em cerca de 25 a 30 m, posicionou-a nas cotas do Nível de Terraço Intermediário. Estudos anteriores mostraram que esta fase de dissecação foi progressivamente mais intensa para jusante (Magalhães Jr, 1993): 40 a 50 m próximo à Serra do Curral, 60 a $70 \mathrm{~m}$ na Depressão de Belo Horizonte e cerca de 80 m na borda da Bacia do Bambuí, em Santa Luzia. Enquanto a espessura média dos registros do Nível de Terraço Intermediário oscilam entre 1,5 a $3 \mathrm{~m}$, à jusante da área a Serra do Curral (Fecho de Sabará) exerceu um importante efeito de represamento na dinâmica sedimentar, resultando em sequências que ultrapassam os 10 $\mathrm{m}$ de espessura.

Outra fase de encaixamento da calha do Rio das Velhas posicionou-a nas cotas relativas aos atuais registros do Nível de Terraço Inferior. A calha entalhou de 5 a $10 \mathrm{~m} \mathrm{em}$ relação ao Nível de Terraço Intermediário, mesma intensidade de dissecação verificada no trecho fluvial à jusante, próximo à Serra do Curral. Aspecto importante na reconstituição da história geomorfológica da bacia do Alto Rio das Velhas é a verificação de evidências de ativação neotectônica após a formação do Terraço Inferior. A análise da distribuição espacial dos registros deposicionais demonstra a existência de significativas rupturas no perfil longitudinal (Figura 5). Os poucos registros do Nível de Terraço Superior não permitiram a detecção de rupturas, como foi anteriormente verifica- do à jusante da área na borda da Bacia do Bambuí (deslocamento tectônico de 40 a 50 m).

Próximo ao distrito de São Bartolomeu, em Ouro Preto, os registros do Nível de Terraço Inferior passam de $990 \mathrm{~m}$ para $985 \mathrm{~m}$ de altitude. Mais à jusante, as cotas se elevam em $14 \mathrm{~m}$, passando de $920 \mathrm{~m}$ para $934 \mathrm{~m}$, evidenciando uma movimentação diferencial de blocos que também abrangeria os registros do Terraço Intermediário (que apresentam distribuição espacial e desnivelamento semelhante neste trecho). As rupturas coincidem com a presença de grandes falhas geológicas de empurrão de direção de direção NE-SW, devendo evidenciar as respostas da dinâmica fluvial à neotectônica.

Magalhães Jr (1993) estimou que a atividade neotectônica teria provocado um desnivelamento de cerca de $10 \mathrm{~m}$ nos registros do Nível de Terraço Intermediário no trecho de Sabará, à jusante da área. Este desnivelamento não atingiu os registros do Nível de Terraço Inferior naquela área. Portanto, parece ter ocorrido uma fase de reativação neotectônica entre a formação dos terraços Intermediário e Inferior no trecho de Sabará. Por outro lado, no trecho à montante daquela área, uma fase distinta de reativação teria ocorrido após a formação do Nível de Terraço Inferior, atingindo também os registros do Nível Intermediário. A movimentação diferencial dos grandes falhamentos regionais explicaria o soerguimento de blocos diferentes, com velocidades diferentes, em momentos distintos. A hipótese da movimentação diferencial de blocos é reforçada pela Figura 5, a qual mostra que o perfil longitudinal do Rio das Velhas corta diversos falhamentos. Estes falhamentos, presentes nas bases cartográficas geológicas, foram transpostos para o perfil e devem demarcar blocos com comportamento tectônico diferencial (taxas de soerguimento diferentes).

Além do desnivelamento dos registros do Nível de Terraço Intermediário, Magalhães Jr (1993) também verificou depósitos falhados (evidências diretas de neotectônica). $\mathrm{Na}$ área de confluência entre o Rio das Velhas e o Córrego da Quarta-Feira, em Santa Luzia, os depósitos encontram-se basculados para NW e o contato gnaisses-aluviões é deslocado por uma falha normal de direção NE-SW e rejeito de $1,5 \mathrm{~m}$.

O comprimento médio dos seixos dos níveis de terraços apresentou redução importante ao longo dos $52 \mathrm{Km}$ do vale na área estudada, a saber (de montante para jusante): Terraço Superior - redução de $15 \mathrm{~cm}$ para $6 \mathrm{~cm}$, Terraço Intermediário - de 20 para $3 \mathrm{~cm}$; Terraço Inferior - de 15 para $3 \mathrm{~cm}$. Isto demonstra a eficiência do desgaste da carga grosseira em cursos d'água de ambientes tropicais. Esta eficiência também é verificada na seleção do material de montante para jusante, dado o predomínio de seixos de quartzo e a redução marcante dos seixos de outras litologias (itabirito, quarzito, filito). Quanto à petrografia dos seixos, a distribuição é heterogênea ao longo do vale, em todos os níveis de 
terraços. Ocorre uma alternância entre o predomínio de seixos de quartzo e de itabirito ao longo do perfil longitudinal, em função da proximidade com a área fonte.

Assim como é reconhecidamente comum em ambientes tropicais úmidos e tectonicamente ativos, os registros sedimentares são fragmentados e não apresentam riqueza de elementos estratigráficos que auxiliem a interpretação dos paleoambientes deposicionais. Depósitos orgânicos ou espessos aluviões argilosos não foram en- contrados nos níveis de terraços, o que denotaria ambientes tropicais úmidos e sistemas fluviais meandrantes. Por outro lado, o fato dos terraços apresentarem abundantes sedimentos grosseiros de canal, relacionados ao grande volume de carga sedimentar de leito, não indica necessariamente condições deposicionais favoráveis ao padrão entrelaçado, já que as fácies grosseiras de canal são, normalmente, mais resistentes à erosão e tendem a resistir mais tempo na paisagem.

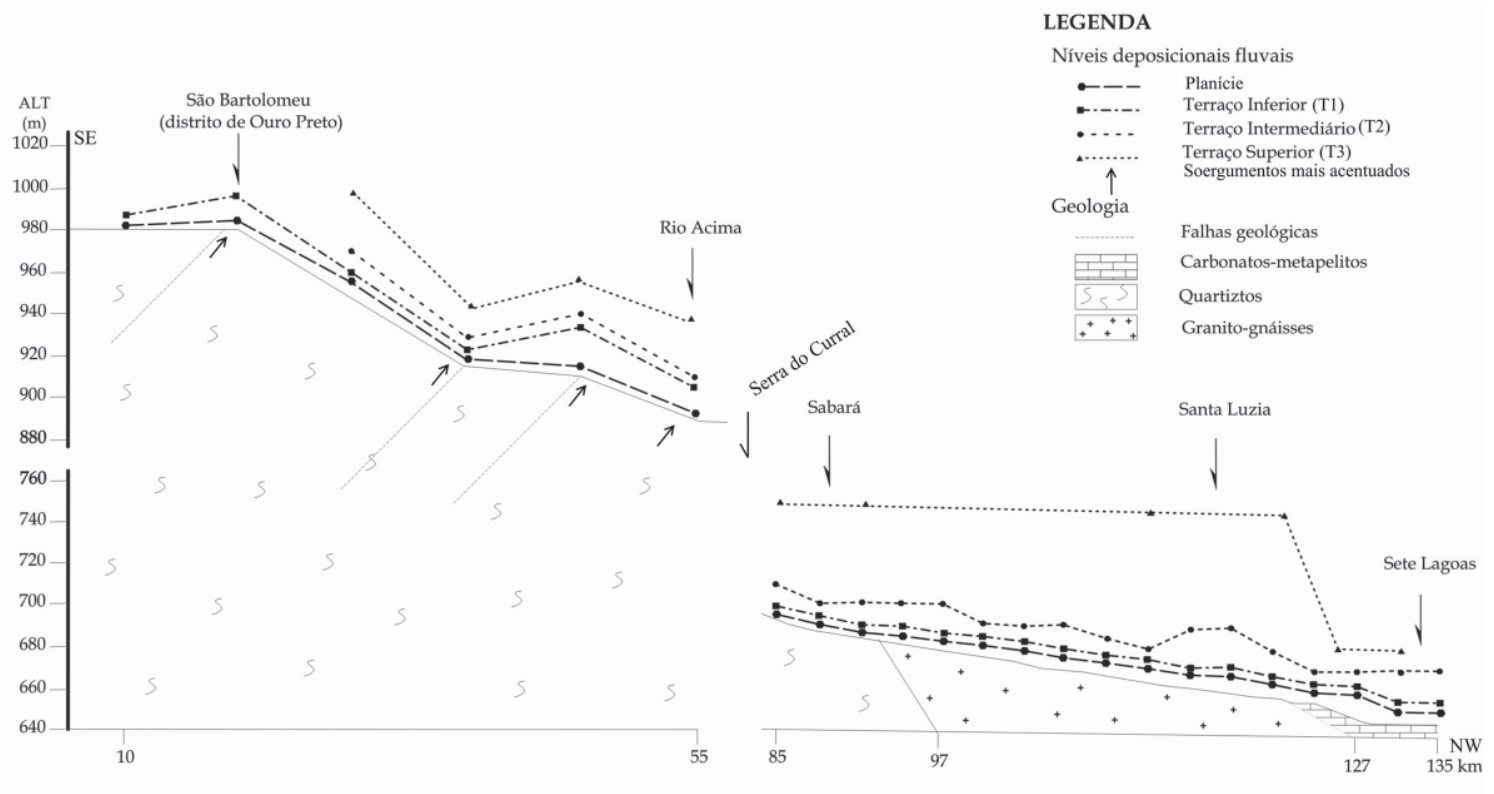

Figura 5 - Distribuição longitudinal dos níveis deposicionais aluviais

A ocorrência de níveis detríticos concrecionados por ferro pode indicar condições úmidas favoráveis às variações do nível freático e a formação de ambientes de oxidação. Estudos no médio e baixo curso do Rio das Velhas indicaram condições deposicionais sob ambiente úmido para os terraços equivalentes aos encontrados neste trabalho.

O fato do trecho estudado corresponder a uma área com abundância de carga sedimentar e neotectônica reconhecidamente atuante, permite supor que as condições originais úmidas e o padrão meandrante vigente pode não ter impedido o desenvolvimento de certos trechos fluviais tendendo à formação de barras de canal e ao entrelaçamento. Datações e análises polínicas podem vir a auxiliar estas interpretações.

O nível de planície apresenta depósitos com abundância de matéria orgânica, mas não turfosos. Predominam sedimentos arenosos que variam de areia fina a grossa. No trecho à jusante da área, Magalhães Jr (1993) identificou sequências sedimentares do nível de planície que apresentam três fases distintas de sedimentação, todas marcadas por fácies de cascalho suportado na base recobertas por fácies arenosa a argiloarenosa. Também encontrou a presença de fácies típicas de meandros abandonados, com estruturas acanaladas preenchidas com sedimentos argilosos orgânicos de cor preta a cinza escuro. Estas fácies não foram encontradas à montante. A Serra do Curral exerceu um papel importante no represamento dos fluxos sedimentares, criando ambientes de menor energia na região de Sabará.

Enquanto no trecho aqui estudado não há variação significativa na textura das fácies sedimentares da planície, na região de Sabará detectou-se uma gradual redução dos depósitos mais finos (argilosos) da primeira para a terceira fase sedimentar do nível de planície. Também ocorre, à montante, o desaparecimento das fácies argilosas orgânicas encontradas na primeira fase. Este fato parece evidenciar as influências humanas na mudança do padrão textural da carga sedimentar, já que atividades como mineração e desmatamentos para fins diversos tendem a provocar aumento relativo no percentual de areia dos depósitos (Magalhães Jr, 1994). A abundância de barras de canal arenosas, principalmente à jusante da confluência do Rio Maracujá, confirma a tendência de arenização da carga sedimentar atual e a migração gradual do padrão fluvial de certos trechos de meandrante típico para entrelaçado. 


\section{Considerações Finais}

O escalonamento dos níveis de terraços ilustra o contínuo soerguimento crustal do Escudo Brasileiro na área, como já verificado por estudos anteriores (Valadão, 1992; Magalhães Jr. e Saadi, 1994). Fato importante, porém, é que o soerguimento regional está associado a uma tectônica diferencial de blocos que gera compartimentos com intensidade de soerguimento distinta. Blocos mais ativos durante o Cenozóico, delimitados por extensas falhas de empurrão, geraram rupturas e anomalias na distribuição espacial dos níveis de terraços Intermediário e Inferior ao longo do perfil longitudinal do vale (Figura 5). Outro reflexo decorre das tipologias do Nível de planície. Nos pontos de movimentação mais intensa, o Nível de planície é do tipo escalonado em relação ao Nível de Terraço Inferior, enquanto nos blocos mais estáveis é do tipo embutido ou recobre o Nível de Terraço Inferior. Magalhães Jr (1993) já havia detectado evidências de tectônica diferencial de blocos no trecho fluvial à jusante da área estudada (entre Sabará e Santa Luzia), a partir da distribuição espacial dos níveis deposicionais e também de falhamentos em depósitos fluviais cenozóicos do Rio das Velhas.

Já a dinâmica fluvial recente foi certamente condicionada pelo efeito encouraçamento que o nível de seixos basal do Nível de Terraço Inferior oferece ao leito do Rio das Velhas. Desde a sua formação, o leito não consegue entalhar e vencer esta barreira detrítica cuja resistência é reforçada pelo concrecionamento dos seixos por ferro. Este fato também explica o recobrimento do T1 pelo Nível de planície em certos trechos, bem como o embutimento da planície no T1. Compreende-se que a dinâmica fluvial pós-Nível de Terraço Inferior é marcada por uma migração lateral que não é acompanhada por um entalhe vertical da calha.

Os resultados demonstram uma riqueza nas tipologias dos níveis deposicionais recentes do alto vale do Rio das Velhas. A dinâmica fluvial no Quadrilátero Ferrífero é condicionada pelo quadro tectônico, pelas atividades humanas e pelos processos de encouraçamento da calha, gerando um comportamento fluvial peculiar em relação aos trabalhos de geomorfologia fluvial no Brasil.

Agradecimentos: Á FAPEMIG e ao CNPq pela viabilização financeira das pesquisas.

\section{Referências Bibliográficas}

Alkmim F. F. \& Marshak S. (1998) Transamazonian Orogeny in the Southern São Francisco Craton Region, Minas Gerais, Brazil: evidence for Peleoproterozoic collision and collapse in the Quadilátero Ferrífero. Precambrian Research, 90; p: 29-98.
Bacellar, L. A. P. (2000) Condicionantes geológicos, geomorfológicos e geotécnicos dos mecanismos de voçorocamento na bacia do rio Maracujá, Ouro Preto, MG. Rio de Janeiro, COPPE/UFRJ, Tese de Doutorado. 226 p.

Barbosa, G. V.; Rodrigues, D. M. S. Quadrilátero Ferrífero. Belo Horizonte: 1967. 130p.

Bridge, J. S. Rivers and Floodplains: Forms, Processes and Sedimentary Record. Blackwell Publishing Limited, Oxford, 2003. 504 p.

Castro, P. T. A.; Alves, J. M.; Ferreira, H. L.; Lana, C.E. (2005). A Influência dos Níveis de Base Locais nas Características Físicas dos Ecossistemas Fluviais: Os Rios Periféricos à Serra do Espinhaço Meridional, MG. In: CONGRESSO BRASILEIRO DE LIMNOLOGIA, 10, Ilhéus. Anais em CD-Rom.

Charlton, R. Fundamentals of Fluvial Geomorphology. (2008). London: Routledge, 234 p.

Chin, A. (1999). The morphologic structure of step-pools in mountain streams. Geomorphology Vol. 27, p.191204.

Dorr, J. V. N; (1969). Desenvolvimento fisiográfico, estratigráfico e estrutural do Quadrilátero Ferrífero, Minas Gerais, Brasil: geologia regional do Quadrilátero Ferrífero, Minas Gerais, Brasil. 204 p.

Duckson Jr, D. W.; Duckson, L. J. (2001). Channel bed steps and pool shapes along Soda Creek, Three Sisters Wilderness, Oregon. Geomorphology, vol.38, p.267-279.

King, L. (1956). A geomorfologia do Brasil Oriental. Revista Brasileira de Geografia, n. 2, p. 3-263.

Kondolf, G. M.; Piegay H. (2003). Tools in Fluvial Geomorphology. Chichester: John Wiley \& Sons, 688 p.

Ladeira, E. A. (1980). Metallogenesis of gold at the Morro Velho, mine and in the Nova Lima district, Quadrilátero Ferrifero, M. G., Brazil. 272p.

Lana, C. E. (2004). Cartografia Integrada de Ecossitemas Lóticos (fluviais) no Alto curso do Rio das Velhas, MG. Dissertação de Mestrado - UFOP. 125 p.

Lana, C. E. ; Castro, P. T. A. (2005) Estudos da proveniência dos sedimentos recentes em um segmento fluvial do alto curso do rio das Velhas - MG. In: X Congresso da Associação Brasileira de Estudos do Quaternário - ABEQUA, 2005, Guarapari. Anais do X Congresso da ABEQUA. 
Latrubesse, E. M.; Franzinelli, E. (2005) The late Quaternary evolution of the Negro River, Amazon, Brazil: implications for island and floodplain formation in large anabranching tropical systems. Geomorphology, Netherlands, v. 70, n. 3-4, p. 372-397.

Latrubesse, E. M.; Stevaux, J.; Sinha, R. (2005) Tropical rivers. Geomorphology, Netherlands, v. 70, n. 34, p. 187-206.

Magalhães Jr, A. P.; Saadi, A. (1994). Ritmos da Dinâmica Fluvial Neo-Cenozóica Controlados por Soerguimento Regional e Falhamento: O Vale do Rio das Velhas na Região de Belo Horizonte, Minas Gerais, Brasil. Geonomos, Belo HorizonteMG; v. 2, n. 1, p. 42-54.

Magalhães Jr, A. P. (1993) Evolução da dinâmica fluvial cenozóica do Alto-médio Vale Rio das Velhas na Região de Belo Horizonte. Belo Horizonte: IGC/ UFMG. 159p. Dissertação de mestrado.

Magalhães Jr, A. P. (1994). Impactos Ambientais em Sistemas Fluviais: a mudança no padrão de sedimentação do Rio das Velhas na região de Belo Horizonte-
MG. Caderno de Filosofia e Ciências Humanas. Belo Horizonte: FNP, ano II, n. 3. p. 25-27.

Magalhães Jr, A. P.; Santos, G. B.; Cherem, L. F. S. (2008). Processos de Encouraçamento da Calha do Alto Rio das Velhas e seus Reflexos na Dinâmica Fluvial Moderna, Quadrilátero Ferrífero, MG. Simpósio Nacional de Geomorfologia, VII, Belo HorizonteMG (no prelo).

Santos, M. L.; Stevaux, J. C. (2000) Facies and architectural analysis of channel sandy macroforms in the upper Paraná River. Quaternary International, v.72, p. 87-94.

Stevaux, J. C.; Barcziyskczy, O.; Medeanic, S.; Nóbrega, M. T. (2006) Characterization and environmental interpretation of a floodplain Holocene paleosoil: Implications for paleohydrological reconstructions in the Upper Paraná River, Brazil. Zeitschrift für Geomorphologie. Supplementband, v. 145, p. 191-206.

Valadão, R. C. ; Silveira, J. S. (1992). Estratigrafia Quaternária e Evolução do Relevo no Complexo de Bação dados preliminares. Revista da Escola de Minas, Ouro Preto/MG, v. 45, n. 1/2, p. 85-87. 